\title{
Attachment style and self-regulation: How our patterns in relationships reflect broader motivational styles
}

\author{
Dan V. Blalock ${ }^{a}$, Alexis T. Franzese ${ }^{\text {b,* }}$, Kyla A. Machell a ${ }^{\text {, Timothy J. Strauman }}{ }^{c}$ \\ a George Mason University, United States \\ ${ }^{\mathrm{b}}$ Elon University, United States \\ c Duke University, United States
}

\section{A R T I C L E I N F O}

\section{Article history:}

Received 6 April 2015

Received in revised form 10 July 2015

Accepted 14 July 2015

Available online 1 August 2015

\section{Keywords:}

Self-regulation

Regulatory focus

Self-discrepancy

Attachment

\begin{abstract}
A B S T R A C T
Individuals orient themselves in relationships using different goals and preoccupations, often conceptualized as four distinct attachment styles (Bartholomew \& Horowitz, 1991). Individuals also orient themselves in the social world more broadly using different motivational preferences and styles. Self-discrepancy theory (Higgins, 1987) and regulatory focus theory (Higgins, 1997) are two frameworks used to conceptualize these motivational styles. In two studies we investigated the extent to which preoccupations in relationships reflected broader life goals. In Study 1, college participants reported attachment style and selfdiscrepancies (ideal and ought selves). In Study 2, community participants reported attachment style and regulatory focus (promotion and prevention orientations). Across two different samples, using distinct but complementary theoretical frameworks, we found a consistent pattern whereby a more approachoriented relationship orientation (secure attachment), was related to a more approach-oriented general life orientation (lower actual-ideal discrepancy and greater promotion focus). Interestingly, attachment style was unrelated to avoidance-oriented motivational styles. These results suggest that motivations within relationships may be specifically related to growth motivations in broader aspects of life.
\end{abstract}

(c) 2015 Published by Elsevier Ltd.

\section{Introduction}

Why are some individuals more prone to form friendships or relationships than others? For people who fear commitment, is their fear limited to a specific relationship, or is it indicative of a broader worldview characterized by risk-aversion? In this paper we look to theories of attachment style and self-regulation to shed light on these questions. Do attachment processes, which begin at birth, spawn a larger array of self-regulatory processes that operate outside of the individual-attachment object relationship? While the cross-sectional findings we present below cannot support a causal hypothesis, we may be able to answer a related question: do relationship patterns and behaviors (attachment) indicate broader themes of more global motivations (self-regulation)? We explore how people's attachment style might be related to the goals and regulatory strategies they use to motivate and control their behavior. Although a comprehensive review of the extensive literature on attachment theory and self-regulation is beyond the scope of this paper, we begin with a brief overview of relevant research.

\footnotetext{
* Corresponding author.

E-mail address: afranzese@elon.edu (A.T. Franzese).
}

\subsection{Attachment}

Attachment theory considers the early bond that develops between caregiver and child as essential for generating schemas about relationships with important others (Bowlby, 1969). The attachment relationship influences expectations about how the world works and how people are supposed to behave and interact (Johnson et al., 2010). Most current research utilizes a two-dimensional model that views attachment as the result of both one's internal model of self (degree to which oneself is worthy of love) and others (degree to which others are worthy of trust; Bartholomew \& Horowitz, 1991). This framework generates four attachment styles (as opposed to the original three proposed by Ainsworth, Blehar, Waters, \& Wall, 1978). Here the secure style is characterized by feeling worthy of love and trusting of others, the preoccupied (or anxious-ambivalent) style is characterized by feeling unworthy of love and trusting of others, the dismissive (or avoidant) style is characterized by feeling worthy of love and untrusting of others, and the fearful style is represents feeling unworthy of love and untrusting of others. ${ }^{1}$ The fearful style is characterized as the least secure and

\footnotetext{
${ }^{1}$ The style previously referred to as anxious-ambivalent by Ainsworth was called preoccupied by Bartholomew and Horowitz, and the style previously deemed avoidant by Ainsworth was classified as dismissive.
} 
least trusting attachment type (Shaver \& Clark, 1994). Even in childhood, the function of the attachment system is to provide a mechanism for regulating both affect and behavior (Shaver \& Mikulincer, 2002). Indeed, securely attached children are more socially and emotionally competent, and demonstrate a better capacity for selfcontrol (Jacobsen, Huss, Fendrich, Kruesi, \& Ziegenhain, 1997).

The same attachment styles and distributions found in childhood are reflected in adult relationships (Hazan \& Shaver, 1987; Priel \& Shamai, 1995). Importantly, adult attachment styles are linked to the ability to form satisfying, connected relationships with others, which is closely linked to well-being and considered by some as central to the human experience (Baumeister \& Leary, 1995). Securely attached adults generally have higher quality relationships, while those who are insecurely attached tend to have volatile, poorly regulated relationships with others (Hazan \& Shaver, 1987; Brennan and Shaver, 1995). Attachment appears to initiate distinct trajectories with life-long implications for adult relationships and broader interpersonal functioning, with effects of early attachment bonds and caregiving styles observed up to 20 years after childhood assessments (Zayas, Mischel, Shoda, \& Aber, 2011). Insecure attachment is associated with maladjustment and poorer functioning in both individual and interpersonal domains across the lifespan. Similarly, a different line of research has proposed that the majority of inter-personal and intra-personal problems derive from a failure to self-regulate (Baumeister, Heatherton, \& Tice, 1994; Tangney, Baumeister, \& Boone, 2004). Thus, attachment may indicate broader self-regulation processes and yet, most research that considers the link between attachment styles and self-regulation has largely favored affect regulation and interpersonal models over broader models of self-regulation.

\subsection{Self-regulation}

The ability to identify and pursue personal goals is what makes us civilized (Freud, 1961). Self-regulation processes enable people to monitor and alter their behavior to accomplish long-term goals. These processes are usually distinguished by whether people are moving toward a desired state or away from an undesired state (Carver, Sutton, \& Scheier, 2000). Previous research has identified links between basic regulatory orientations and attachment style. Securely attached adults tend to engage in approach-oriented behaviors in response to stressful situations that represent either self or relational threats while insecurely attached adults (specifically those with an preoccupied attachment style) rely more heavily on avoidance-oriented behaviors (for a review, see Park, 2010). This suggests that when people feel confident in themselves and in their relationships (i.e., securely attached), they may be more likely to adopt a focus on growth and advancement. Both attachment styles and motivational tendencies seem to have important implications for the goals that guide interpersonal behavior (Gable \& Impett, 2012). This line of research provides converging evidence for the notion that attachment styles are linked with motivational orientations, at least in a relational context.

Other research suggests that attachment style plays a role in people's ability to modulate their affective responses to a variety of stimuli (e.g., Rowe \& Carnelley, 2003). People who are securely attached tend to capitalize on positive experiences and emotions, leading to a positive view of themselves and their past. People who have a preoccupied attachment tend to be overwhelmed by negative thoughts and memories, leading to a very poor view of themselves and their past (Mikulincer, 1998b). Interestingly, dismissive people do not appear to be influenced by positive or negative experiences, yet they recall almost solely positive memories, possibly as a defense for their own positive, yet fragile, view of themselves (Mikulincer, 1995; Mikulincer \& Sheffi, 2000). These findings highlight the influence of attachment style on the affective component of self-regulation and suggest the possibility that attachment may impact regulatory styles more broadly.
Two related theories of self-regulation-self-discrepancy theory (SDT; Higgins, 1987) and regulatory focus theory (RFT; Higgins, 1997)-provide a framework for exploring the connections between attachment style and self-regulation more broadly. Both SDT and RFT suggest that self-regulation is facilitated by comparisons between the current perception of self and positive and negative possibilities for the future self. At the individual differences level, these theories differentiate people who are focused primarily on advancement and growth from those who are concerned primarily with protection and security. SDT focuses on how these differences emerge in the context of views about the self, while RFT considers how these differences emerge in the context of views about the larger social world.

\subsubsection{Self-discrepancy theory}

SDT is a theory of self-regulation involving standards for selfevaluation called self-guides, specifically the ideal self and the ought self (Higgins, 1987). A person strives to change their behavior to either become more like their ideal self, which is what they aspire or dream to be, or become more like their ought self, which is what they feel responsible or obligated to be. Regulation guided by the ideal self tends to be focused on approaching desired ends states, which has been associated with a decreased actual-ideal discrepancy (Higgins, Roney, Crowe, \& Hymes, 1994). Regulation guided by the ought self is characterized by a focus on avoiding undesired end states, and has been associated with a decreased actual-ought discrepancy (see Higgins, 1998 for a review).

Previous research has linked attachment style with types of selfdiscrepancies. Mikulincer (1995) found that securely attached adolescents had less ideal-actual and less ought-actual self-discrepancy than their insecurely attached counterparts, which suggests that individuals who are securely attached may be more effective at aligning their actual selves with these self-guides than those with an insecure attachment style. These findings are consistent with research on attachment and affect-regulation. Insecure attachment styles are associated with negative affect (Mikulincer, 1995), which prompts specific regulatory behaviors to minimize that negative affect. Substantial self-discrepancies are likewise thought to lead to negative affect (Higgins, 1987) and associated regulatory behaviors. It would seem that both attachment style and the self-guides of SDT are tools for assessing the self, and motivate change through undesirable states caused by negative evaluations. Yet it is still unclear whether the parallels between attachment and regulation exist solely in the context of affective responses to interpersonal stimuli (as the affect-regulation literature might suggest), or also extend to reflect an individual's overarching worldview (as RFT would imply).

\subsubsection{Regulatory focus theory}

RFT (Higgins, 1997) extends the concept of self-guides posited by SDT into broader regulatory orientations. Referred to as promotion and prevention, these motivational systems are postulated to influence cognitive processes associated with decision-making, as well as more general worldviews. These orientations map on to the ideal and ought selves of SDT, respectively (see for example, Higgins, 1997; Strauman, 1996). A promotion focus is characterized by a person's motivation to "make good things happen," of which striving to attain an ideal goal is a specific example. A prevention focus, on the other hand, is also characterized by a motivation to attain positive outcomes, but instead by "keep bad things from happening" (Higgins, 1997), where striving to attain an ought goal is a specific example. Individual differences in regulatory focus are thought to emerge over childhood and adolescence from interactions with significant others (Higgins \& Silberman, 1998; Manian, Papadakis, Strauman, \& Essex, 2006).

Thus, some researchers have speculated that secure attachment may be linked to a promotion orientation (Mikulincer, Shaver, Gillath, \& Nitzberg, 2005), while insecure styles should correspond with a prevention orientation (Smith, Murphy, \& Coats, 1999). Indeed, promotion/ 
prevention orientations have recently been linked to the attachment dimensions of anxiety and avoidance in romantic relationships (Winterheld \& Simpson, 2011). Moreover, recent work has demonstrated that promotion-focused individuals are more likely than prevention-focused individuals to seek out, positively evaluate, and pursue romantic partners (Finkel, Molden, Johnson, \& Eastwick, 2009; Woltin \& Yzerbyt, 2015) - behaviors much more consistent with secure than insecure attachment. These proposals are consistent with the literature demonstrating associations between attachment and self-discrepancies.

\subsection{The present research}

Previous work has shown that attachment is reliably associated with affective components of self-regulation, and there is growing empirical and theoretical evidence to support the notion that attachment styles are associated with the broader worldviews captured by RFT. However, no study has directly tested these associations in adult samples using both SDT and RFT. Moreover, these hypothesized associations also have yet to be tested using the four-style model of attachment that includes the fearful style. In the present research, we consider both SDT and RFT with attachment theory. By analyzing each of these associations, we hope to distinguish whether any specific attachment style is reliably associated with specific self-regulatory styles, in the form of promotion/prevention orientations.

These research questions were addressed through two crosssectional studies designed to explore associations among the constructs of interest. In Study 1, individuals' self-discrepancies were measured as part of a larger experimental paradigm, where these individuals were exposed to positively valenced trait attributes based on previously described self-discrepancies. No data from the experimental manipulation was used for this study. Similarly, Study 2 measured individuals' regulatory focus as part of a larger battery of questionnaires. In both studies, attachment style and motivational style (i.e., self-discrepancies or regulatory focus) were measured early on to prevent biased or altered responses that may arise from the experimental manipulations or order effects.

\section{Study 1: attachment styles and self-discrepancies}

\subsection{Associations between attachment style and self-discrepancy}

The purpose of this study was twofold: 1) to replicate previous research on the association between attachment style and selfdiscrepancies, and 2) to extend this research by considering these associations with the four-style model of attachment (which includes the fearful style) and by exploring this association beyond adolescents, in an very diverse adult population.

We predicted that secure attachment will be related to significantly lower actual-ideal (indicating a greater focus on ideal self) and significantly higher actual-ought self-discrepancies (indicating a lesser focus on ought self) than insecure attachment. This includes the newer style of fearful attachment. People who are securely attached and more prone to value growth and advancement should be more likely to pursue and use their ideal selves as a guide for their behavior. Conversely, people who are insecurely attached and more concerned with the potential for risk and negative outcomes should be more likely to pursue and use their ought selves as a guide for behavior. In other words, secure attachment, which has been linked in past research with approachoriented motivations, should lead people to pursue advancement goals aligned with achieving desired end-states. Insecure attachment, which has been linked with a tendency toward avoidance and risk aversion, should lead people to pursue preventative goals aligned with avoiding undesired end-states.
Hypothesis 1. Secure attachment style will be associated with lower actual-ideal discrepancies than all three insecure attachment styles. The three insecure attachment styles will be associated with lower actualought discrepancies than secure attachment style.

\subsection{Method}

\subsubsection{Participants}

Two hundred and eighty three participants (55\% female) provided complete data on measures of age, sex, self-discrepancies and attachment style. ${ }^{2}$ Descriptive statistics for the sample and primary measures of interest are provided in Table 1. Participants were recruited through the Psychology department subject pool at a university in the southeast and through a social psychology subject pool (open to community members) established through the same university. Psychology subject pool participants received one credit toward a psychology class requirement, and community subject pool participants were compensated tendollars for their time. The sample was predominantly composed of college aged (mean age $=19.8$ years, $\mathrm{SD}=3.2$ ) psychology subject pool participants $(\mathrm{n}=212)$.

\subsubsection{Measures}

Participants completed a computerized questionnaire protocol that included the following measures: demographic questions, the Relationship Questionnaire (RQ; Bartholomew \& Horowitz, 1991), and a computerized modification of the Selves Questionnaire (SQ; Higgins, 1987; Computerized Selves, Shah \& Higgins, 2001). The study was administered on computers using MediaLab software.

2.2.2.1. Attachment style. Attachment style was assessed using the RQ. Although the fearful style is not always included in research on attachment theory, the multi-dimensional measurement proposed by Bartholomew and Horowitz has transformed how scholars conceptualize the construct of attachment (see Smith et al., 1999 for examples). Similar two-dimensional models have been used to organize attachment styles (Brennan, Clark, \& Shaver, 1998). The new twodimensional model also demanded a change in measurement. One of the more commonly used measures assessing the four styles is the Relationship Questionnaire (RQ; Bartholomew \& Horowitz, 1991), which is used in the current study. Other measures such as the Experiences in Close Relationships Questionnaire (ECR; Brennan et al., 1998) are also widely used, but the RQ was selected for its brevity and for evidence that it is appropriate for use in cross-sectional research (Sibley, Fischer, \& Liu, 2005).

The RQ is a short 5-item questionnaire that asks the participant to pick one of four paragraphs that best describes him or herself. Each paragraph represents a different attachment style. After this initial choice, the participant then rates each of the four paragraphs on a 1 to 7 scale of how each description corresponds with his or her general relationship style ( 1 being the least, 7 being the most). In order to assess participants' attachment styles, we coded participants based on the relationship style paragraph they endorsed most highly on the 1 to 7 Likert scale. This strongly corresponded with their initial choice of which of the four paragraphs best described them $\left(\chi^{2}=472.35, r=\right.$ $.81, \mathrm{p}<.001)$. In order to precisely measure discrete attachment styles, the 68 participants who rated multiple attachment styles as equally reflective of their general relationship style were removed from the analyses. Moreover, these removed individuals were not significantly different from the rest of the sample on any important demographic variables. This led to a distribution of attachment styles in our sample (total $\mathrm{N}=215$ ) similar to what would be expected in the general

\footnotetext{
2 Two participants were excluded from the current data set due to missing data on the measure of attachment style used in this study.
} 
Table 1

Descriptive statistics for Study 1 participants $(\mathrm{N}=283)$.

\begin{tabular}{lllll}
\hline & M & SD & Range & Percent \\
\hline Age (years) & 19.8 & 3.24 & $18-39$ & \\
Sex & & & & \\
$\quad$ Male $(\mathrm{n}=128)$ & & & & 45.2 \\
$\quad$ Female $(\mathrm{n}=155)$ & & & 54.8 \\
Ethnicity & & & & 52.3 \\
$\quad$ White $(\mathrm{n}=148)$ & & & 13.8 \\
$\quad$ Black $(\mathrm{n}=39)$ & & & 25.8 \\
$\quad$ Asian $(\mathrm{n}=73)$ & & & 7.1 \\
$\quad$ Other $(\mathrm{n}=20)$ & & & & 1.1 \\
$\quad$ Not reported $(\mathrm{n}=3)$ & 3.58 & 1.04 & $1-6.4$ & \\
Ideal discrepancy & 3.42 & 1.16 & $1-6.8$ & \\
Ought discrepancy & & & &
\end{tabular}

Note: Scores on ideal and ought importance can range from 1-7, and scores on ideal and ought discrepancy can range from 1-7.

Other includes participants who identified as Hispanic, biracial, multiracial, or a group not captured in the classifications of White, Black, and Asian.

population (Secure $\mathrm{N}=114$; Preoccupied $\mathrm{N}=24$; Dismissive $\mathrm{N}=28$; Fearful $\mathrm{N}=49$ ).

2.2.2.2. Self-discrepancies. Self-discrepancies were measured with the computerized version of the Selves Questionnaire (Shah \& Higgins, 2001), which differs slightly from the pen-and paper version. The Selves Questionnaire is a semi-structured questionnaire asking each participants to write 10 words each describing their actual self, ideal self, and ought self, then asking them to rate on a 1 to 4 scale how much they actually possess, would want to possess, or feel they need to possess each trait, respectively ( 1 being the least, 4 being the most) The computerized version of the SQ used in this study asks participant to list five words each describing their ideal self, and ought self, asked in alternating fashion. Respondents are prompted to provide additional responses if they use the same words to describe both their ideal and ought selves, as it is desirable for the ideal and ought terms to be unique from one another. Participants are then asked a series of questions about the terms including their importance (1-7 scale), and how far they are from possessing the term (1-7 scale). Self-discrepancy scores were based on responses to the latter questions about the distance from self-guides. Both the original SQ and the computerized version demonstrate strong test-retest reliability ( $r$ 's $>.7$ ).

\subsubsection{Procedure}

Participants were invited to sign-up for a 35 to 45 -minute session in which he or she completed a consent form and was assigned to a computer station to complete the study protocol. Each computer station was separated from its neighboring stations by a divider, affording privacy, and participants had unlimited time to complete the study protocol. A member of the research team was available throughout the duration of the study to address any concerns or questions participants might have. Upon completion of the study participants received either payment or course credit. Participants were informed that compensation (cash or course credit) would be provided regardless of whether they fully completed the study protocol.

\subsection{Results and discussion}

First we examined zero-order correlations (presented in Table 2) to evaluate initial associations between study variables. A larger actualideal discrepancy was negatively related to secure attachment $(\mathrm{r}=-.22, \mathrm{p}<.01)$ and positively related both a preoccupied attachment $(r=.18, \mathrm{p}<.01)$, and a fearful attachment $(r=.15, \mathrm{p}<.01)$, but did not show significant associations with the dismissive attachment style. Interestingly, actual-ought discrepancy was completely unrelated to any attachment style, with no correlation higher than .08 . This provides some evidence that, while attachment may relate to ideal discrepancies, it may not be associated with ought discrepancies. While sex showed almost no associations with the relevant constructs (except fearful attachment, $r=-.13, \mathrm{p}<.05$ ), age was positively related to several constructs, most notably both ideal $(r=.16, \mathrm{p}<.05)$ and ought discrepancies $(r=.15, \mathrm{p}<.05)$. Nevertheless, previous research has implicated both age (Konrath, Chopik, Hsing, \& O'Brien, 2014) and sex (Bartholomew \& Horowitz, 1991) as potential moderators of attachment style, and so their main effects and all possible interactions were included in regression models.

Because the focus of this paper is on secure versus insecure attachment, predominant attachment style was dummy coded such that the comparison group was secure attachment. Actual-ideal discrepancy and actual-ought discrepancy means for each attachment style are presented in Table 3. Two multivariate regressions were then run (Table 4), including dummy-coded attachment style, centered sex, centered age, and all relevant 2- and 3-way higher order interactions. The first model predicting actual-ideal discrepancy indicated that secure attachment $(b=3.42$ ) yielded significantly smaller actual-ideal discrepancies than both a fearful attachment style ( $b=0.44, \mathrm{p}=.02)$ and a dismissive attachment style ( $b=0.48, \mathrm{p}=.03$ ), and marginally smaller actualideal discrepancies than a preoccupied attachment style $(b=0.39$, $\mathrm{p}=.09$ ). The second model predicting actual-ought discrepancies, however, indicated no significant differences between secure and insecure attachment styles. Although the inclusion of higher-order interaction terms greatly penalized our models (Ideal Discrepancy Adj. $R^{2}=$ .05 ; Ought Discrepancy $R^{2}=.01$ ), we wanted to provide a strong test against interactions with demographic variables that have been shown to relate to attachment styles.

The present correlational data involving self-discrepancy partially supported our hypotheses about the associations between attachment style and ideal and ought discrepancies. Secure attachment was significantly correlated with lower actual-ideal discrepancy $(r=-.22$,

Table 2

Correlations between demographics, self-discrepancies, and attachment styles.

\begin{tabular}{|c|c|c|c|c|c|c|c|c|}
\hline Variables & Age & Male & IdealDis & OughtDis & Secure & Preocc & Dismiss & Fearful \\
\hline Age & - & & & & & & & \\
\hline Male & $.03^{\dagger}$ & - & & & & & & \\
\hline Ideal discrepancy & $.16^{*}$ & .00 & - & & & & & \\
\hline Ought discrepancy & $.15^{*}$ & -.03 & $.57^{* * *}$ & - & & & & \\
\hline Secure & .01 & .01 & $-.22^{* *}$ & -.04 & - & & & \\
\hline Preoccupied & -.08 & .06 & $.18^{* *}$ & -.08 & $-.40^{* * * *}$ & - & & \\
\hline Dismissive & $.29^{* *}$ & .08 & -.01 & .08 & $-.37^{* * *}$ & $-.17^{* *}$ & - & \\
\hline Fearful & -.06 & $-.13^{*}$ & $.15^{* *}$ & .06 & $-.53^{* * *}$ & $-.24^{* * *}$ & $-.22^{* * *}$ & - \\
\hline
\end{tabular}

Note. Correlations with attachment style are based off each participant's continuous Likert scale endorsement for each style.

$\dagger \mathrm{p}<.1$.

* $\mathrm{p}<.05$.

** $\mathrm{p}<.01$.

$* * * \mathrm{p}<.001$. 
Table 3

Attachment style and self-discrepancy means.

\begin{tabular}{lllll}
\hline Mean SD scores & Secure & Preoccupied & Dismissive & Fearful \\
\hline Ideal discrepancy & $3.42_{\mathrm{a}}$ & $3.81_{\mathrm{c}}$ & $3.90_{\mathrm{b}}$ & $3.86_{\mathrm{b}}$ \\
Ought discrepancy & 3.44 & 3.32 & 3.25 & 3.22 \\
\hline
\end{tabular}

Note: $\mathrm{a}, \mathrm{b} \mathrm{p}<.01 ;{ }_{\mathrm{a}, \mathrm{c}} \mathrm{p}<.10$. Significant differences are between subscripts $\mathrm{a}$ and $\mathrm{b}$, and $a$ and $c$.

$\mathrm{p}<.01)$. This negative correlation indicates that securely attached participants perceived less distance between their actual selves and their ideal selves. This suggests that securely attached individuals are more likely to focus on ideal self-guides, and are successful at aligning their behavior with what they dream or aspire to be. Both preoccupied and fearful attachment, on the other hand, were associated with more actual-ideal discrepancy $(r=.18, \mathrm{p}<.01 ; r=.15, \mathrm{p}<.01$, respectively). That is, participants with high ideal discrepancy were more likely to have a preoccupied or fearful attachment style. This suggests that preoccupied or fearfully attached participants may be less successful at aligning their actual selves with their idealized version of themselves. Securely attached individuals $(M=3.42)$ had significantly lower ideal discrepancy means than dismissive $(\mathrm{M}=3.90)$ and fearfully attached individuals ( $\mathrm{M}=3.86$ ), and marginally lower ideal discrepancy than preoccupied individuals $(\mathrm{M}=3.81)$. This trend provides some support that secure attachment is related to ideal goals, since secure individuals were far less discrepant than insecure individuals.

Our hypothesis that individuals with insecure attachments would report lower actual-ought discrepancies when compared with individuals with secure attachments was not supported. There were no significant differences among the secure and insecure attachment styles in terms of mean scores measuring the perceived distance between the actual self and the ought self. It should be noted, however, that given the nature of the sample (e.g., not selected on the basis of high levels of self-discrepancy and/or chronic emotional distress), associations involving self-discrepancy and attachment style would be likely to be modest in magnitude. However, the results suggests that attachment style may be less important for determining whether individuals are motivated by risk-aversion than it is for determining whether individuals are motivated by growth and advancement. This possibility is explored further in Study 2, which uses an alternative measure of regulatory focus that expands our study of motivational styles beyond the self to encompass larger worldviews.

\section{Study 2: attachment styles and regulatory focus}

The purpose of this second study was to explore associations between RFT and attachment theory by examining correlations among

Table 4

Dummy-coded multiple regression results.

\begin{tabular}{lllrrr}
\hline Variables & Adj. $R^{2}$ & Weight $(b)$ & \multicolumn{1}{l}{ 95\% C.I. } & $t$-Value & p-Value \\
\hline DV: Ideal discrep. & .05 & & & & .146 \\
Secure attachment & & 3.42 & $3.23-3.61$ & 35.48 & $<.001$ \\
Preoccupied att. & & 0.39 & $-0.07-0.84$ & 1.69 & .093 \\
Dismissive att. & & 0.48 & $0.05-0.91$ & 2.21 & .028 \\
Fearful att. & 0.44 & $0.08-0.79$ & 2.41 & .017 \\
Sex & 0.04 & $-0.33-0.43$ & 0.25 & .802 \\
Age & 0.05 & $-0.01-0.11$ & 1.79 & .076 \\
DV: Ought discrep. & .01 & & & & .352 \\
Secure Attachment & & 3.44 & $3.23-3.66$ & 32.18 & $<.001$ \\
Preoccupied att. & & -0.12 & $-0.63-0.38$ & -0.48 & .634 \\
Dismissive att. & & -0.19 & $-0.67-0.28$ & -0.80 & .424 \\
Fearful att. & -0.12 & $-0.64-0.39$ & -0.48 & .635 \\
Sex & -0.07 & $-0.49-0.35$ & -0.34 & .736 \\
Age & 0.03 & $-0.03-0.09$ & 0.37 & .365
\end{tabular}

Note: Models also controlled for all higher order 2- and 3-way interactions among main effect variables, which penalized the adjusted $R^{2}$ values. No interaction effects approached significance. The full models can be seen in the supplementary materials. individual differences in promotion and prevention orientation and each of the four attachment styles. This study extends Study 1 by examining how attachment relates to regulatory views of the world in addition to regulatory views of oneself, as characterized by SDT. That is, Study 1 demonstrated that securely attached people are closer to being what they want to be, as their actual selves are closer to their ideal selves. Study 2 attempts to uncover whether this is because they are striving for rewards (promotion orientation) and succeeding, or because they are protecting against losses (prevention orientation) and succeeding. Further, we wanted provide an additional test of our hypothesis that insecure attachment should be associated with greater prevention-focused, avoidant motivational styles. Because the results from Study 1 failed to support the notion that insecure attachment led to greater reliance on ought self-guides, Study 2 explores this same question using a different measure of self-regulation. Thus we are exploring the robustness of our differential finding across theoretical frameworks and samples.

We also hoped to examine the associations between regulatory styles and attachment style in a sample of established adults as a means to evaluate whether the associations between attachment and regulatory views can be generalized beyond a college student sample. Importantly, the attachment relationship, which is initially derived in childhood, may come about differently in different cohorts. Parenting styles have varied dramatically in the last 50 years (see for example Rutherford, 2009), yet the goal remains to produce a securely attached, optimally functioning person. With that in mind, the present study examined secure attachment across different cohorts and parenting styles due to our oversampling of middle-aged and older adults, in addition to a traditional college-aged sample.

\subsection{Associations between attachment style and regulatory orientation}

Study 2 sought to extend Study 1 by examining the relations between attachment style and broader regulatory orientations and worldviews. We expected to observe higher mean levels of promotion scores and lower mean levels of prevention scores in securely attached participants than insecurely attached participants. This is consistent with characterizations of a secure attachment figure as a base from which one can go out and explore (Ainsworth et al., 1978). Likewise, securely attached people react better to positive stimuli and are less affected by negative stimuli (Mikulincer, 1998a; Mikulincer \& Sheffi, 2000), and thus should be motivated more by opportunities to achieve something desirable and less by opportunities to prevent adverse events. Dismissive individuals in particular may have lower promotion orientations because they have a lesser need for achievement and focus less on mastery goals, dismissing the challenges and excitement associated with them as undesirable (Elliot \& Reis, 2003). Moreover, dismissive individuals' high avoidance may result in a stronger prevention orientation to prevent being let down by others.

Preoccupied individuals, however, may have higher prevention orientations because react more strongly to negative stimuli (Mikulincer, 1998a), and resort to hypervigilance strategies to protect against harmful interactions (Mikulincer \& Sheffi, 2000). Moreover, preoccupied individuals' high dependence on others may result in a weaker promotion orientation as they do not trust themselves enough to strive after appetitive goals. Finally, fearful individuals are characterized by the negative aspects of both preoccupied (high dependence) and dismissive attachment (high avoidance), and so we expect that these individuals are likely to be too submissive to attain a promotion orientation and instead maintain a prevention orientation because they are afraid of being hurt. Stated succinctly:

Hypothesis 2. Secure attachment style will be associated with greater promotion orientation and lower prevention orientation than all three insecure attachment styles. 


\subsection{Method}

\subsubsection{Participants}

Participants included one hundred and seventy-seven individuals (61\% female) in a larger study (Franzese, 2007) who had data on measures of regulatory focus, attachment style, sex, and age. ${ }^{3}$ The larger study involved assessing the relationship between selfregulation and authenticity across various ages, using primarily a battery of paper-and-pencil questionnaires. Descriptive statistics for the sample and primary measures of interest are provided in Table 5. The sample represented both younger and older adults. The younger adult sample (mean age $=32.4$ years, $S D=6.7$ ) was recruited through an advertisement in a campus publication at a university in the Southeast. Older adult participants were recruited through an aging center subject registry at the same university, and were predominantly over age 65 (mean age $=72.5$ years, SD $=$ 5.8). The diverse age range of this sample provides a valuable extension to Study 1 . Together, the two studies include data from diverse age groups, which allows for important generalizability of any significant associations between attachment and self-regulation. All participants received five dollars with their questionnaires, which they were invited to keep regardless of whether or not they completed the survey.

\subsubsection{Procedure}

Questionnaire packets, which included a consent form, were mailed to potential participants $(\mathrm{N}=177)$ who were asked to mail completed questionnaire packets back to the researcher.

\subsubsection{Measures}

Questionnaire packets completed by study participants included a series of questionnaires in addition to basic questions about demographic characteristics. Questionnaires relevant to this study include the Relationship Questionnaire (RQ; Bartholomew \& Horowitz, 1991) and the Regulatory Focus Questionnaire (RFQ; Higgins, 1997).

3.2.3.1. Attachment style. As in Study 1, attachment style was measured with the $\mathrm{RQ}$, a short 5-item questionnaire that asks the participant to pick one of four paragraphs that best describes him or herself and then rate each of the paragraphs on a 1 to 7 scale of how each description corresponds with his or her general relationship style (1 being the least, 7 being the most). Each paragraph represents a different attachment style. In order to accurately assess participants' attachment styles, as in the previous study, we coded participants based on their strongest endorsement of relationship style, which strongly corresponded with their initial endorsement between attachment style paragraphs $\left(\chi^{2}=386.76, r=.94, p<.001\right)$. In order to more precisely measure discrete attachment styles, the 22 participants whose strongest endorsement was for multiple attachment styles were removed from the analyses. As with Study 1, these individuals were not significantly different on any important demographic variables. This again led to a distribution of attachment styles in our sample (total $\mathrm{N}=150$ ) similar to what would be expected (Secure $\mathrm{N}=75$; Preoccupied $\mathrm{N}=18$; Dismissive $\mathrm{N}=35$; Fearful $\mathrm{N}=22$ ).

3.2.3.2. Regulatory focus. To assess individual differences in regulatory focus, we used the Regulatory Focus Questionnaire (RFQ; Higgins, 1997), which divides promotion and prevention each into two subscales: history and success. The RFQ measures both the regulatory

\footnotetext{
3 The majority of individuals excluded from the current analyses were excluded due to missing data on the measure of attachment style used in the study $(n=19)$. Individuals missing either all or the majority of items on the regulatory focus measures were excluded from the analyses $(n=4)$. For individuals missing a sole item or small number of regulatory focus items, means were imputed for the missing items.
}

Table 5

Descriptive statistics for Study 2 participants $(\mathrm{N}=177)$.

\begin{tabular}{lllll}
\hline & $\mathrm{M}$ & $\mathrm{SD}$ & Range & Percent \\
\hline Age (years) & 50.1 & 20.85 & $24-84$ & \\
$\quad$ Younger adults $(\mathrm{n}=99)$ & 32.4 & 6.7 & $24-53$ & 55.9 \\
$\quad$ Older adults $(\mathrm{n}=78)$ & 72.5 & 5.8 & $63-84$ & 44.1 \\
Sex & & & & 39.0 \\
$\quad$ Male $(\mathrm{n}=69)$ & & & & 61.0 \\
$\quad$ Female $(\mathrm{n}=108)$ & & & & \\
Ethnicity & & & & 69.5 \\
$\quad$ Caucasian $(\mathrm{n}=123)$ & & & & 30.5 \\
$\quad$ African-American $(\mathrm{n}=54)$ & 3.74 & 0.58 & $1.6-5$ & \\
Promotion success & 3.41 & 0.69 & $1.4-5$ & \\
Prevention success & & & & \\
\hline
\end{tabular}

orientation a person most likely exhibited in their past and the ways they were socialized (history), as well as a person's current evaluation of their progress in self-regulation (success). We did not consider the relations between prevention or promotion history and attachment style because our measure of attachment is focused on current relationships. The 26-item questionnaire asks participants to rate how true or frequent statement such as "I feel like I have made progress toward being successful in my life" are on a 1 to 5 scale ( 1 being the least, 5 being the most). The 26 items reflect 4 aspects of regulatory orientation: prevention history, prevention success, promotion history, and promotion success. In the present study, only the prevention $(\alpha=.69)$ and promotion $(\alpha=.64)$ success subscales demonstrated acceptable internal consistency.

\subsubsection{Results and discussion}

First we examined zero-order correlations (presented in Table 6) to evaluate initial associations between study variables. Promotion orientation was positively related to secure attachment $(r=.34$, $\mathrm{p}<.001)$ and negatively related to both preoccupied $(r=-.23$, $\mathrm{p}<.01)$ and fearful attachment $(r=-.32, \mathrm{p}<.001)$, but did not show a significant association with dismissive attachment. Interestingly, prevention orientation was completely unrelated to any attachment style, with no correlation higher than .08 . This provides some evidence that, while attachment may relate to promotion orientation, it may not be associated with prevention orientation. While sex showed no associations with the relevant constructs, age was positively related to prevention orientation $(r=.25, \mathrm{p}<.001)$ and dismissive attachment $(r=.12, \mathrm{p}<.05)$, and negatively related to fearful attachment $(r=-.19, \mathrm{p}<.01)$. To keep analyses parallel with Study 1, age, sex, and all possible interactions were included in regression models.

In keeping with the focus on secure versus insecure attachment, predominant attachment style was again dummy coded such that the comparison group was secure attachment. Promotion and prevention orientation means for each attachment style are presented in Table 7. Two multivariate regressions were then run (Table 8), including dummy-coded attachment style, centered sex, centered age, and all relevant 2- and 3-way higher order interactions. The first model predicting promotion orientation indicated that secure attachment $(b=3.89$ ) yielded significantly higher mean promotion scores that preoccupied attachment $(b=-0.41, \mathrm{p}=.02)$, dismissive attachment $(b=-0.25, \mathrm{p}=.01)$, and fearful attachment $(b=-0.40, \mathrm{p}<.01)$. The second model predicting prevention orientation, however, indicated no significant differences between secure and insecure attachment styles. Finally, although the inclusion of higher-order interaction terms greatly penalized our models (Promotion Orientation Adj. $R^{2}=.07$; Prevention Orientation $R^{2}=$ $.06)$, we wanted to provide a strong test against interactions with demographic variables that have been shown to relate to attachment styles. 
Table 6

Correlations between demographics, regulatory orientations, and attachment styles.

\begin{tabular}{|c|c|c|c|c|c|c|c|c|}
\hline Variables & Age & Male & Pro & Pre & Secure & Preocc & Dismiss & Fearful \\
\hline Age & - & & & & & & & \\
\hline Male & $.01^{\dagger}$ & - & & & & & & \\
\hline Promotion & -.09 & .05 & - & & & & & \\
\hline Prevention & $.25^{* * *}$ & .11 & $.32^{* * * *}$ & - & & & & \\
\hline Secure & .04 & .02 & $.34^{* * * *}$ & .08 & - & & & \\
\hline Preoccupied & -.17 & .04 & $-.23^{* *}$ & -.04 & $-.36^{* * *}$ & - & & \\
\hline Dismissive & $.12^{*}$ & .02 & -.01 & -.02 & $-.59^{* * *}$ & $-.21^{* *}$ & - & \\
\hline Fearful & $-.19^{* *}$ & -.10 & $-.32^{* * *}$ & -.05 & $-.40^{* * *}$ & $-.23^{* *}$ & $-.22^{* *}$ & - \\
\hline
\end{tabular}

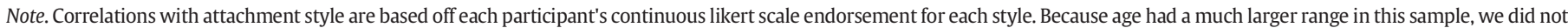
expect the correlations with relevant constructs to replicate sample 1.

${ }^{\dagger} \mathrm{p}<.1$.

* $\mathrm{p}<.05$.

** $\mathrm{p}<.01$.

*** $\mathrm{p}<.001$.

Our hypotheses about the association between attachment style and regulatory focus were partially supported. While we did not find support for our hypotheses that the three insecure attachment styles would have higher prevention focus scores than a secure style, we did find evidence that secure attachment was associated with a promotion focus. Securely attached individuals' promotion scores $(M=3.89)$ were significantly higher than preoccupied individuals' ( $M=3.47)$, fearful individuals' $(\mathrm{M}=3.49)$, and dismissive individuals' $(\mathrm{M}=3.63)$ promotion scores. Further, when examining individuals' continuous ratings of endorsement for each attachment style, two insecure styles were negatively related to promotion focus scores: preoccupied $(r=-.23$, $\mathrm{p}<.01)$ and fearful attachment $(r=-.32, \mathrm{p}<.001)$. These findings provide tentative support for the notion that insecure attachment may be negatively associated with a promotion focus. These analyses suggest that individuals differ in their regulatory orientation according to their attachment style. Specifically, we find higher mean promotion scores among securely attached individuals than among the other three groups, as predicted.

The three insecure attachment styles did not significantly differ from the secure style in terms of prevention focus. Though this did not support our hypothesis, this finding converges with results from Study 1 and suggests that attachment style may be more important for appetitive motivations than it is for avoidance motives. Just as we found no evidence for differences in actual-ought discrepancy in Study 1, the results from Study 2 did not support the notion that attachment style would be related to a prevention focus. Though our initial hypotheses were only partially supported, these results do suggest that attachment style is associated with particular aspects of individuals' broader worldviews, as measured according to RFT. Implications of these findings are considered further in the general discussion below.

\section{General discussion}

The purpose of this research was to determine the extent to which attachment style is related to self-regulation. Two cross-sectional studies explored relations between the four attachment styles, selfdiscrepancies, and promotion/prevention orientations in samples of adults. In Study 1, we considered how attachment style was related to people's self-views. Individuals who were securely attached had fewer discrepancies between their actual self and the ideal self they were striving toward. Study 2 extended Study 1 to explore the associations

Table 7

Attachment style and regulatory orientation means.

\begin{tabular}{lllll}
\hline Mean RF scores & Secure & Preoccupied & Dismissive & Fearful \\
\hline Promotion success & $3.89_{\mathrm{a}}$ & $3.47_{\mathrm{b}}$ & $3.63_{\mathrm{c}}$ & $3.49_{\mathrm{b}}$ \\
Prevention success & 3.49 & 3.31 & 3.36 & 3.38 \\
\hline
\end{tabular}

Note: $\mathrm{a}, \mathrm{b} \mathrm{p}<.01 ; \mathrm{a}, \mathrm{c} \mathrm{p}<.05$. Significant differences are between subscripts $a$ and $b$, and $a$ and $c$. between attachment style and broader regulatory orientations. A secure attachment style was linked with greater promotion focus than the insecure attachment styles. Taken together, these findings suggest that not only is attachment related to the way people view both themselves and the world, but it is also relevant for understanding broader themes of self-regulation and motivation. Securely attached people seem to be oriented toward promotion focused goals and perceive themselves as closer to attaining their ideal selves. Insecurely attached people, on the other hand, have less promotion-focused goals and perceive themselves as farther away from attaining their ideal selves. Contrary to our hypotheses, insecure attachment style was not significantly associated with larger actual-ought discrepancies or a greater prevention focus. This could indicate that attachment style may be more important for appetitive, rather than preventative, strivings, a finding that differs from previous empirical work on these relationships. This speaks to the nature of the theory, as the two foci are not opposite ends of a single spectrum. Evidence supports the relative independence of approach versus avoidance motivations (Carver et al., 2000). The current data suggest that attachment style is correlated with high and low ends of a promotion orientation, but is inconclusive regarding the association between prevention orientation and attachment style.

Why might the link between attachment and motivation only exist for appetitive motivational styles? Attachment theory characterizes secure attachment as resulting from a responsive caregiver providing consistent support necessary for an infant to explore the world around them. In other words, secure attachment implies a solid foundation from which to strive toward ideals. A solid foundation, however, does

Table 8

Dummy-coded multiple regression results.

\begin{tabular}{llclrr}
\hline Variables & Adj. $R^{2}$ & Weight $(b)$ & 95\% C.I. & t-Value & p-Value \\
\hline DV: Promotion & .07 & & & & .035 \\
Secure attachment & & 3.89 & $3.77-4.01$ & 63.40 & $<.001$ \\
Preoccupied att. & & -0.41 & -0.84 to -0.15 & -2.43 & .016 \\
Dismissive att. & & -0.25 & -0.50 to -0.06 & -2.69 & .008 \\
Fearful att. & & -0.40 & -0.97 to -0.17 & -2.93 & .004 \\
Sex & & -0.00 & $-0.23-0.26$ & -0.03 & .980 \\
Age & -0.01 & -0.01 to -0.00 & -2.17 & .031 \\
DV: Prevention & .06 & & & & .043 \\
Secure attachment & & 3.49 & $3.34-3.63$ & 45.86 & $<.001$ \\
Preoccupied att. & & -0.18 & $-0.50-0.33$ & -1.02 & .310 \\
Dismissive att. & & -0.13 & $-0.50-0.03$ & -0.98 & .328 \\
Fearful att. & & -0.11 & $-0.20-0.78$ & -0.61 & .543 \\
Sex & 0.07 & $-0.24-0.34$ & 0.46 & .644 \\
Age & 0.01 & $0.00-0.01$ & 2.02 & .045
\end{tabular}

Note: Models also controlled for all higher order 2- and 3-way interactions among main effect variables, which penalized the adjusted $R^{2}$ values. No interaction effects approached significance. The full models can be seen in the Supplementary materials. The upper estimate for the age predicting Promotion and lower estimate for age predicting Prevention is rounded. Actual values are -0.0005 and -0.0001 , respectively. 
not necessarily preclude the need for or benefits of precaution. As an example, consider two individuals: the first person is growth-oriented and motivated by advancement, and is also concerned with taking precautions to prevent negative outcomes (i.e. high in both promotion and prevention). The second person is growth-oriented and motivated by advancement but is not concerned with taking precautions (i.e. high in promotion and low in prevention). While previous research would suggest we cannot assume the first individual is securely attached (because we have one piece of evidence for and one piece of evidence against), our current research indicates that both individuals can be (and in fact are both likely to be) securely attached based on their growth-orientation. In fact, these findings align better with regulatory theories that demonstrate the large degree of independence between orientations such as promotion and prevention (Higgins et al., 2001).

Both Study 1 and Study 2 supported our hypothesis that secure attachment was related to more approach-oriented regulatory orientations. In Study 1, securely attached participants believed their actual self aligned more closely with their ideal self than insecurely attached participants; in Study 2, securely attached participants reported a greater focus on promotion-oriented goals than insecurely attached participants. Taken together, these findings suggest that secure attachment is linked to views about both the self and world that are motivated by the potential for growth and opportunities. Stated differently, securely attached people may be more concerned with how to advance and better themselves.

\subsection{Theoretical implications}

An approach-oriented and purposeful orientation across domains of life has been shown to be beneficial in many other areas, including one's overall health and well-being (McKnight \& Kashdan, 2009). Prioritizing hopes, dreams, and aspirations, and guiding your behavior such that opportunities for growth are maximized, may be the key for getting the most out of life. For example, people involved in romantic relationships describe less actual-ideal discrepancy than their single counterparts. They also report higher psychological well-being (Campbell, Sedikides, \& Bosson, 1994). Dispositional tendencies toward approach behaviors are linked with short-term goals in relationships that are focused on growth and advancement, which predict increases in relational satisfaction over time (Gable \& Impett, 2012). In addition, entrepreneurs who value growth and development tend to be better than entrepreneurs who are preoccupied with maintaining security at cultivating larger business networks that in turn produce more revenue (Pollack, Forster, Johnson, Coy, \& Molden, 2015). This general appetitive orientation appears to confer benefits across many life domains.

A secure attachment style might provide a foundation of inner resources that allows individuals to consider what the ideal version of themselves looks like, and take the steps to organize their choices and behavior to strive for that ideal. Individuals with insecure attachment styles may be less sensitive to this potential for reward and positive experience (Mikulincer, 1995). When people lack the inspiration of an ideal self and place less value on opportunities for advancement, they may extract fewer benefits from their experiences in relationships, occupation, and recreational activities, and experience lower psychological well-being as a result. Recent research indicates that there the number of securely attached individuals may be decreasing (Konrath et al., 2014), a concerning finding given the results of the current studies, which would suggest that a decrease in secure attachment would be associated with a decrease in adaptive regulatory style.

If patterns of goals and preoccupations exist within life domains (attachment in relationships), across life domains (regulatory focus), and within oneself (self-discrepancies), we can expect the effects of these orientations to be ubiquitous. Indeed, as research has already demonstrated a promotion focus to uniquely predict purpose in life and goal directedness (Grant \& Higgins, 2003), secure attachment may be another marker of this underlying appetitive orientation.
Thus, secure attachment in adult relationships might actually be important and useful information in anything from job interviews to health decisions about the most effective type of treatment to engage in (c.f. aptitude by treatment interactions; Smith \& Sechrest, 1991). In addition, there may be an intergenerational connection between attachment style and regulatory style through parenting. That is, parents' own attachment styles influence the ways in which they parent (Jones, Cassidy, \& Shaver, 2015). That parenting, in turn, influences the regulatory style of the children (Manian et al., 2006).

\subsection{Limitations and future directions}

These findings should be interpreted in light of several limitations. Most importantly, the cross-sectional nature of our data does not allow us to infer direction of causality when it comes to attachment style and regulatory focus. Future research should examine how these associations function longitudinally, and would allow for a true test of the notion that attachment style, with its roots in infancy, spawns a larger array of regulatory patterns that persist across the lifespan. More nuanced measures of attachment would also enhance our understanding of the association with self-regulation. The attachment construct has traditionally been conceptualized as categorical, a view that is reflected in the measurement method used in the current study. Although our measure of attachment style may have attenuated the variance explained by forcing individuals into a single category, we still found meaningful results with what can be considered a conservative test. However, it is possible that considering within-person differences in attachment style or using a more dimensional approach, such as the one presented by Bartholomew and Horowitz (1991), would inspire questions related to stability of attachment style across relationships and contexts, and how this might influence self-regulatory styles and behaviors in different domains.

Though we cannot determine a causal order, these associations observed in this study provide insight into the intersections of how we relate to others (attachment) and how this might affect or be affected by our own motivations and strategies for attaining goals (self-regulation). This work further supports the distinctness of promotion and prevention orientations, as attachment style relates solely to one and not the other. Perhaps more importantly, our results suggest that how we operate in relationships transcends to other areas of life.

\section{Appendix A. Supplementary data}

Supplementary data to this article can be found online at http://dx. doi.org/10.1016/j.paid.2015.07.024.

\section{References}

Ainsworth, M.D.S., Blehar, M.C., Waters, E., \& Wall, S. (1978). Patterns of Attachment: Assessed in the Strange Situation and at Home. Hillsdale, NJ: Erlbaum.

Bartholomew, K., \& Horowitz, L.M. (1991). Attachment styles among young adults: a test of a four-category model. Journal of Personality and Social Psychology, 61, $226-244$.

Baumeister, R.F., Heatherton, T.F., \& Tice, D.M. (1994). Losing Control: How and Why People Fail at Self-regulation. San Diego, CA: Academic Press.

Baumeister, R.F., \& Leary, M.R. (1995). The need to belong: desire for interpersonal attachments as a fundamental human motivation. Psychological Bulletin, 117, 497-529.

Bowlby, J. (1969). Attachment, Vol. 1, New York: Basic Books.

Brennan, K.A., Clark, C.L., \& Shaver, P.R. (1998). Self-report measurement of adult attachment. In J.A. Simpson, \& W.S. Rholes (Eds.), Attachment Theory and Close Relationships (pp. 46-76). New York: The Guilford Press.

Brennan, K.A., \& Shaver, P.R. (1995). Dimensions of adult attachment, affect regulation, and romantic relationship functioning. Personality and Social Psychology Bulletin, 21(3), 267-283.

Campbell, W.K., Sedikides, C., \& Bosson, J. (1994). Romantic involvement, self-discrepancy, and psychological well-being: a preliminary investigation. Personal Relationships, $1,399-404$

Carver, C.S., Sutton, S.K., \& Scheier, M.F. (2000). Action, emotion, and personality: emerging conceptual integration. Personality and Social Psychology Bulletin, 26, 741-751. 
Elliot, A.J., \& Reis, H.T. (2003). Attachment and exploration in adulthood. Journal of Personality and Social Psychology, 85, 317-331.

Finkel, E.J., Molden, D.C., Johnson, S.E., \& Eastwick, P.W. (2009). Regulatory focus and romantic alternative. In J.P. Forgas, R.F. Baumeister, \& D.M. Tice (Eds.), Self-regulation: Cognitive, Affective, and Motivational Processes (pp. 319-335). New York, NY: Psychology Press.

Franzese, A. T. (2007). To thine own self be true? An exploration of authenticity. Ph.D. Unpublished Dissertation. Durham, NC: Department of Sociology, Duke University.

Freud, S. (1961). Civilization and its discontents (1930). The Standard Edition of the Complete Psychological Words of Sigmund Freud, 21, 59-145.

Gable, S.L., \& Impett, E.A. (2012). Approach and avoidance motives and close relationships. Social and Personality Psychology Compass, 6, 95-108.

Grant, H., \& Higgins, E.T. (2003). Optimism, promotion pride, and prevention pride as predictors of quality of life. Personality and Social Psychology Bulletin, 29, 1521-1532.

Hazan, C., \& Shaver, P.R. (1987). Romantic love conceptualized as an attachment process. Journal of Personality and Social Psychology, 52, 511-524.

Higgins, E.T. (1987). Self discrepancy: a theory relating self and affect. Psychological Review, 94, 319-340.

Higgins, E.T. (1997). Beyond pleasure and pain. American Psychologist, 52, 1280-1300.

Higgins, E.T. (1998). Promotion and prevention: regulatory focus as a motivational principle. In M.P. Zanna (Ed.), Advances in Experimental Social Psychology, Vol. 30. (pp. 1-46). New York: Academic Press.

Higgins, E. T., Friedman, R. S., Harlow, R. E., Idson, L. C., Ayduk, O. N., \& Taylor, A. (2001). Achievement orientations from subjective histories of success: Promotion pride versus prevention pride. European Journal of Social Psychology, 31(1), 3-23.

Higgins, E.T., Roney, C.J.R., Crowe, E., \& Hymes, C. (1994). Ideal versus ought predilections for approach and avoidance distinct self-regulatory systems. Journal of Personality and Social Psychology, 66, 276-286.

Higgins, E.T., \& Silberman, I. (1998). Development of regulatory focus: promotion and prevention as ways of living. In J. Heckhausen, \& C.S. Dweck (Eds.), Motivation and Self-regulation Across the Life Span (pp. 78-113). New York, NY: Cambridge University Press.

Jacobsen, T., Huss, M., Fendrich, M., Kruesi, M.J., \& Ziegenhain, U. (1997). Children's ability to delay gratification: longitudinal relations to mother-child attachment. The Journal of Genetic Psychology, 158, 411-426.

Johnson, S.C., Dweck, C.S., Chen, F.S., Stern, H.L., Ok, S.J., \& Barth, M. (2010). At the intersection of social and cognitive development: internal working models of attachment in infancy. Cognitive Science, 34, 807-825.

Jones, J.D., Cassidy, J., \& Shaver, P.R. (2015). Parents' self-report attachment styles: a review of links with parenting behaviors, emotions, and cognitions. Personality and Social Psychology Review, 19, 44-76.

Konrath, S.H., Chopik, W.J., Hsing, C.K., \& O'Brien, E. (2014). Changes in adult attachment styles in American college students over time: a meta-analysis. Personality and Social Psychology Review, 18, 326-348.

Manian, N., Papadakis, A.A., Strauman, T.J., \& Essex, M.J. (2006). The development of children's ideal and ought self-guides: the influence of parenting on individual differences in guide strength. Journal of Personality, 74, 1619-1645.

McKnight, P.E., \& Kashdan, T.B. (2009). Purpose in life as a system that creates and sustains health and well-being: an integrative, testable theory. Review of General Psychology, 13, 242-251.

Mikulincer, M. (1995). Attachment style and mental representation of the self. Journal of Personality and Social Psychology, 69, 1203-1215.

Mikulincer, M. (1998a). Attachment working models and the sense of trust: An exploration of interaction goals and affect regulation. Journal of Personality and Social Psychology, 74, 1209-1224.
Mikulincer, M. (1998b). Adult attachment style and affect regulation: strategic variations in self-appraisals. Journal of Personality and Social Psychology, 75, 420-435.

Mikulincer, M., Shaver, P.R., Gillath, O., \& Nitzberg, R.A. (2005). Attachment, caregiving, and altruism: boosting attachment security increases compassion and helping. Journal of Personality and Social Psychology, 89, 817-839.

Mikulincer, M., \& Sheffi, E. (2000). Adult attachment style and cognitive reactions to positive affect: a test of mental categorization and creative problem solving. Motivation and Emotion, 24, 149-174.

Park, L.E. (2010). Responses to self-threat: linking self and relational constructs with approach and avoidance motivation. Social and Personality Psychology Compass, 4, 201-221.

Pollack, J.M., Forster, W.R., Johnson, P.D., Coy, A., \& Molden, D.C. (2015). Promotion-and prevention-focused networking and its consequences for entrepreneurial success. Social Psychological and Personality Science, 6, 3-12.

Priel, B., \& Shamai, D. (1995). Attachment style and perceived social support: effects on affect regulation. Personality and Individual Differences, 19, 235-241.

Rowe, A., \& Carnelley, K.B. (2003). Attachment style differences in the processing of attachment-relevant information: primed-style effects on recall, interpersonal expectations, and affect. Personal Relationships, 10, 59-75.

Rutherford, M.B. (2009). Children's autonomy and responsibility: an analysis of childrearing advice. Qualitative Sociology, 32, 337-353.

Shah, J.Y., \& Higgins, E.T. (2001). Regulatory concerns and appraisal efficiency: the genera impact of promotion and prevention. Journal of Personality and Social Psychology, 80, 693-705.

Shaver, P., \& Clark, C.L. (1994). The psychodynamics of adult romantic attachment. In J.M Masling, \& R.F. Bornstein (Eds.), Empirical Perspectives on Object Relations Theories (pp. 105-156). Washington, DC: American Psychological Association.

Shaver, P.R., \& Mikulincer, M. (2002). Attachment-related psychodynamics. Attachment \& Human Development, 4, 133-161.

Sibley, C.G., Fischer, R., \& Liu, J.H. (2005). Reliability and validity of the revised experiences in close relationships (ECR-R) self-report measure of adult romantic attachment Personality and Social Psychology Bulletin, 31, 1524-1536.

Smith, E.R., Murphy, J., \& Coats, S. (1999). Attachment to groups: theory and measurement. Journal of Personality and Social Psychology, 77, 94-110.

Smith, B., \& Sechrest, L. (1991). Treatment of aptitude $\times$ treatment interactions. Journal of Consulting and Clinical Psychology, 59, 233-244.

Strauman, T.J. (1996). Stability within the self: a longitudinal study of the structural implications of self-discrepancy theory. Journal of Personality and Social Psychology, 71 1142-1153.

Tangney, J.P., Baumeister, R.F., \& Boone, A.L. (2004). High self-control predicts good adjustment, less pathology, better grades, and interpersonal success. Journal of Personality, 72, 271-324.

Winterheld, H.A., \& Simpson, J.A. (2011). Seeking security or growth: a regulatory focus perspective on motivations in romantic relationships. Journal of Personality and Social Psychology, 101, 935-954.

Woltin, K.A., \& Yzerbyt, V. (2015). Regulatory focus in predictions about others Personality and Social Psychology Bulletin, 41, 379-392.

Zayas, V., Mischel, W., Shoda, Y., \& Aber, J. L. (2011). Roots of Adult Attachment Maternal Caregiving at 18 Months Predicts Adult Peer and Partner Attachment. Socia Psychological and Personality Science, 2(3), 289-297. 